\title{
An Improved Quantitative Model for Evaluating Pork Price Fluctuation Trend and the Impaction in China: an Empirical Analysis between 2004-2014
}

\author{
Chong Zhou \\ Research Centre of Northern Anhui Urban-rural Integration, Suzhou University, \\ Suzhou city, Anhui province, 234000, China
}

\begin{abstract}
The development of the Internet provides more opportunities for the agricultural supply chain, especially the application of large data. This paper analyzes the change of the price of pork from 2004 to 2013, and analyzes the impaction of the price fluctuation on the domestic demand and the income of the farmers, and puts forward the corresponding countermeasures on the basis of the analysis. To promote the healthy and stable development of the pig industry, it should be from five aspects: first, actively encourage large-scale breeding, and do a good job of prevention and control of swine industry. The second is to encourage the development of the company added farmers' breeding form. Through large-scale pig industry companies and farmers in the form of cooperation, can enable farmers to enhance market risk resilience. Third is the establishment of production, supply, and sales integration of supply chain; Four is to make full use of the Internet to achieve the integration of the supply chain of pigs. Five is the use of international trade to maintain the healthy development of the pig industry. Pork prices in the downturn, can reduce the downward pressure on domestic pork prices through exports, the price of pork can be too high to adjust the domestic pork prices too fast.
\end{abstract}

Keywords: Food price, Consumption demand, Farmers income, Price Fluctuation

\section{Introduction}

Pork industry plays an important role in the national economy and the people's livelihood. In recent years, pork prices have been frequent and violent fluctuations, excessive price fluctuations are not conducive to the healthy development of the pork industry, but also affect the consumption of residents. Agricultural production operators lack of effective and timely market information, can only bear the market risk of fluctuations in pork prices [1]. Government management department is currently only passive response, the policy effect is often not satisfactory. Therefore, the research on the price fluctuation of pork and the government price regulation policy can make us understand the pork market more deeply, and then we can take effective measures and means to reduce the price fluctuation of pork market. Because of its rich in protein, fat, carbohydrates, calcium, iron, phosphorus and other ingredients, pork has been loved by people [2]. In recent years, the impact of the purchase of live pigs, large-scale farming, other alternative livestock products, economic fluctuations and other factors, the price of pork in China is also showing a varying degree of volatility. Fluctuations in the price of pork not only affect the demand of pork, but also through the value of the transmission of the chain directly affect the income of pork production households. We will discuss this issue in this problem.

First of all, for the cause of the fluctuation of the price of pork, the study of many domestic experts and scholars mainly concentrated in two areas of supply and demand and circulation. In supply and demand, Xiao Hua (2014) believes that the main reason for 
the change in pork prices is the supply of farmers through the change in the proportion of the market to adjust the supply of the market [3]. He describes it in farmer's pig raising scale close to the limit of the case, the amount of pig herds could not increase greatly, in this case, farmers only through change since the proportion of food and to respond to pork prices, thus affecting the pork market supply, resulting in changes in the price of pork. Chen (2012) pointed out that the main reason for the fluctuations in the price of live pigs and pork is a highly decentralized way of feeding [4]. The mechanism of the formation mechanism of the pork price is systematically and comprehensively studied. Jiqin (2011) pointed out that prices for inputs, through the production cost of the impact of hog producers of live pigs production, and the influence of the pork supply, and ultimately cause a role of pork price fluctuation [5]. In addition, many experts have carried out relevant studies, for example, Guo(2012) through the study of the cyclical fluctuations of pork, the conclusion that a year, China's pork prices fell mainly due to the slow income growth of low-income groups, the price decline and the shortage of pork quality caused by the shortage of demand[6]. Other factors, such as scientific and technological progress, the emergence of new breeding technology, and so on, these factors make the production efficiency of pig rising, so that the output of pig increased, and eventually led to the reduction of pork prices. Liu (2011) pointed out that the opportunity cost of the farmers' support, resulting in the self-sufficiency of production resources is almost zero, thus, the bulk of farmers' low price elasticity [7]. So farmers cannot reduce the production, so that the presence of the retail pork market supply, which makes the market supply of pork is rigid, and increased the volatility of the market price of pork and pork market trends [8] In addition, there are also many scholars believe that the traditional festivals, climate and diseases, and so may be an important factor affecting China's pork price fluctuations [9]. Circulation, experts believe that due to the circulation system is not smooth, plus farmer pig the size is relatively small and most are decentralized rearing, self-produced selfmarketing mode and after slaughter pigs and prescribed scribing region operations and other reasons, so, due to the slaughter plant so monopolized the pork prices and the market, making many retail investors cannot be timely access to market information, on the market reaction is not sensitive enough factors, resulting in pig production and sales in the region distribution uneven.

\section{Literature Review}

\subsection{Agricultural Product Price Formation Mechanism}

The cost and profit of the various industrial chains are combined to determine the final price of agricultural products. The formation of an agricultural product prices generally include: key producers, middlemen initial acquisition and transportation, processing and packaging, processors, retailers and wholesalers wholesale retail. The final product price is determined by the cost of each chain and the profit distribution [10]. Consumer price is the price of the final product and service. When the cost of producing the product increases, it is bound to be transmitted to the consumer price.

The equilibrium price of agricultural products is determined by the balance of demand and supply of agricultural products. Supply refers to the sum of a certain amount of goods that the producer is willing and able to sell at a certain price level at a given time. Demand is defined as the sum of the amount of goods purchased by the consumer, which is willing and able to buy at a specified price level at a particular period. Under the action of market mechanism, the price of commodity is the price of market supply and demand equilibrium. Price changes mainly come from the supply and demand changes, including production costs, related technologies, related commodity prices and producer expectations and other factors that affect the supply of products, the impact of changes in 
demand, including consumption, income, alternative prices, consumer preferences, consumer preferences and so on[11].

The pork industry chain includes the following steps: pig breeding, including the construction of breeding ground, the purchase of the piglets, the growth of piglets and the sale of live pigs. Costs include direct investment (piglets and feed), indirect investment costs (vaccine injection), labor costs, breeding sites and the cost of pig sales including the market contact, including the market contact, loading, transportation and other processes. The cost includes the short distance transportation, the loading fee and the labor cost and the broker profit. Pig slaughter and processing, including the slaughter of pigs, classification, processing and refrigeration process, the cost of artificial fees, slaughter site fees and cold storage, including pork from the slaughter and cold point out to the consumer market all acts, including market management fees, loss, labor costs, related packaging.

\subsection{Price Fluctuation Theory}

Changes in process or state fluctuations in the economy refer to the economic variables in the time series of continuous. Modern economic cycle theory holds that economic fluctuation is the impact of economic variables on the time series, and then through a variety of random variables, and then through a mechanism of communication, composite, amplification and the formation of a cyclical rise or fall trend. Lucas in 1977 when talking about the number of macroeconomic operation state time series: on the view of technology, economic variables around its trend of motion can be used in a low order differential equation with random interference to describe, these movements in the cycle and amplitude are shown to be inconsistent, that is, they are not exactly similar to the natural sciences sometimes appear in the deterministic fluctuations. And Brand and Fisher think that the fluctuation is the economic variable deviation from the long-term trend of the sequence related changes. The analysis of the fluctuation state mainly through the volatility, the peak, the valley, the fluctuation cycle and other technical indicators to analyze, in addition to the volatility of the duration, the reversal of the characteristics, the asymmetry and other fluctuations. At present, the research method of the fluctuation is mainly to eliminate the trend of the two order moment analysis and the establishment of quantitative economic model and so on.

According to the length of the time series, the economic fluctuation can be divided into long-term and short-term fluctuations. Short term fluctuations are the deviation from the long-term trend of the economic reality, the extent of the deviation is far away, the magnitude of the economic fluctuation is larger, and the stability of the economic operation is lower. There are two major factors that affect the price of pork, which is the internal transmission mechanism of the market. Including: the interpretation of the cobweb theory of supply and demand and the price is the core motivation of pork price fluctuations; the market system is not perfect the pork industry lead to fluctuations in the price of pork is hidden by the system; pig production costs is an important reason for the price fluctuations of pork. Two is the impact of external shocks on the market price fluctuations; the market system is the external random or nonrandom factors causing the price of agricultural products. Including: the external impact factor of the disease is the biggest factor of the fluctuation of the pork, and the transmission effect of the international related factors is the external factor that causes the price fluctuation. The external impact mechanism is mainly the short-term fluctuations in the price fluctuation, and the abnormal point in the process of the price fluctuation.

\subsection{National Regulation and Control Policy}

National regulation and control policy will have an important impact on the fluctuations of pork prices. Generally speaking, the mechanism of action includes two 
aspects: direct and indirect. Directly refers to the state directly to the pork industry to support subsidies and intervention adjustments. Including indirect credit policy, electricity and so on production material price adjustment, the overall trend of national economy influence on the effect of the price of pork. At present, the national macro control means and methods of the pork market, including tax incentives, financial subsidies, pig insurance and scientific research and technical support, but the problem is: the introduction of a hasty passive, and not enough stability, the time choice of regulatory policy is not scientific and reasonable, the effect of the market is lagging behind, it is difficult to guide and adjust the market changes. In addition, choose to be established from the reserve function of frozen pork reserve capacity is limited, not enough to stabilize the market. Overall, the policy adjustment of the production and risk averse policy effect is still relatively weak, it may cause a more violent price fluctuations. From the information dissemination and guidance mechanism, the pig production and price data collection is not complete, not timely, product price and production data is not smooth, the market early warning and analysis mechanism is not perfect, cannot be right and timely support for farmers' scientific and reasonable. In addition, some local governments for the implementation of regional protection of pig slaughter, processing enterprises, resulting in poor circulation of live pigs and the market is not fair competition intensifies; the market has increased the volatility of the price of pork.

For the macro policy of pork price adjustment, we believe that: the current macrocontrol policies lack of stability and initiative, the choice of policy support point is not scientific and reasonable, the lack of policy on the price of pork, the overall development of the pork industry lack of coordination. The main policy suggestions should be started from the main pig production support policy to support and strengthen the pig production industry development policy to strengthen the pork market support.

\section{Pork Price Fluctuation}

\subsection{Pork Price Fluctuation Trend Stage Division}

Price is the monetary performance of commodity prices, Marx's theory of labor value: "the price is the monetary name of the labor in the commodity". Generally speaking, the price is the exchange rate between the seller and the buyer, and that is, the number of the money in a particular commodity. Under the action of market economy mechanism, the price of commodity fluctuates with the fluctuation of supply and demand. In the market system, the price has been reflected and adjusted the supply and demand of goods, to achieve the effective allocation of resources. Price is an indicator of the relationship between supply and demand. According to the market supply and demand information, commodity producers adjust production management decision-making and resource allocation, thus effectively promote the reasonable balance between supply and demand. At the same time, the price level is reflected by the value of the commodity. The price level also affects the consumer demand for a commodity, demand direction and structure. In the case of other factors, the market price of a commodity is inversely proportional to the demand of the market. Price reflects the situation and efficiency of market resources allocation, so that the country can effectively intervene in the market economy activities. Especially those that rely on market forces to balance supply and demand, such as agricultural products, and so on. When a commodity supply shortage, leading to price increases, the state can use the relevant regulatory means to encourage and promote the expansion of the scale of production, increase the supply of goods, adjust the supply and demand balance, can effectively stabilize the market supply and demand, reduce the instability factors, promote market efficiency. 
From 2004 to 2013, the price of pork in China showed obvious characteristics of the stage. The author takes the monthly price as the unit to analyze, selects the annual pork price performance typical month as January, April, July, October four months, and carries on the analysis, has selected the 10 year 40 month's pork price, the concrete trend as shown in figure 1.

According to the fluctuation trend of pork price fluctuations in the ten years, the author divides the price trend of pork into three stages: year $2004-2008$ s the first stage, the price of pork is showing a trend of S, and the price of pork in 2008-2011 as the second stage, the price of $2011-2013$ is third stages, and the price of pork in October is 1 stages.

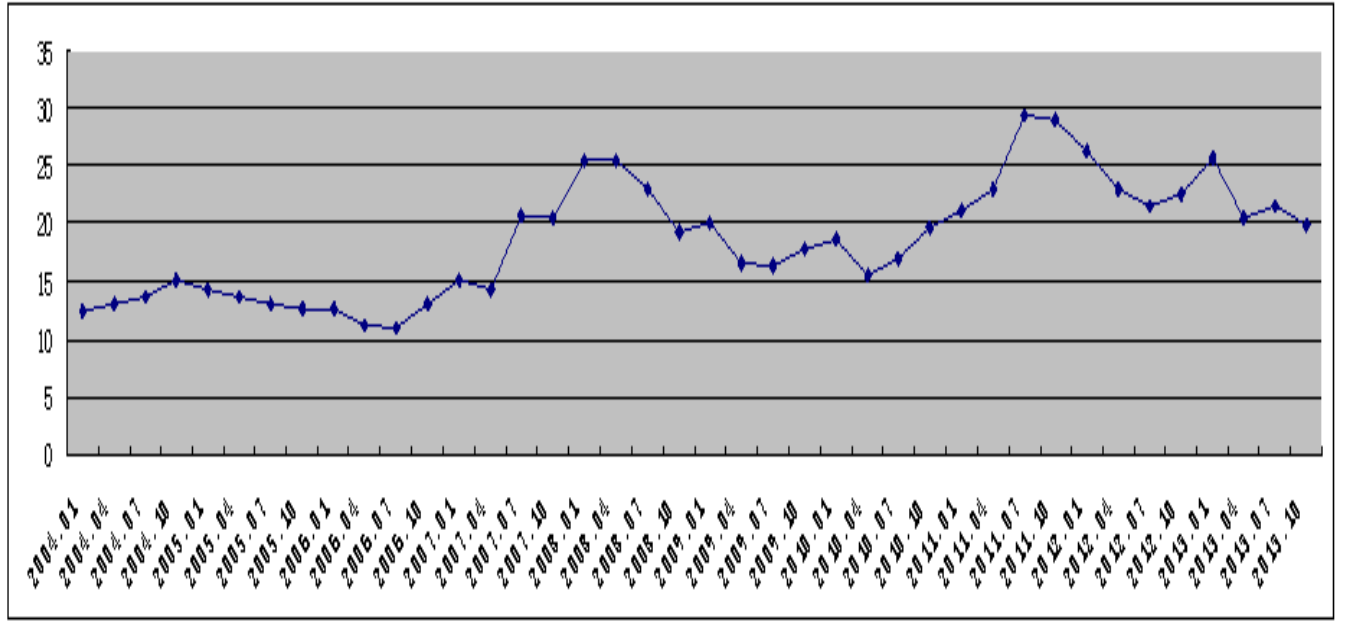

Figure 1. Trend Chart of Pork Price Fluctuation during 2004-2013

\subsection{Pork Prices and Time Fitting Model}

The pork market in China is an important part of the market of agricultural products, pork market is deep contradiction is the main contradiction between market and weak production, the price of pork by changes in market supply and demand, production costs and seasonal changes and other types of emergencies such as, price fluctuations are frequent, serious impact on the stability of the pork market. Agricultural production operators in the market information asymmetry is not equal to the lack of effective and timely market information, the supply and price changes cannot be an effective response to the supply and price fluctuations in the market, the market risk. Government management departments at present is only a passive response to the main control, scientific and effective regulation and control, cannot effectively grasp the inherent laws of the fluctuations of pork, and find the key points and the best intervention point, the policy effect is often not satisfactory.

According to the three stages of pork price difference, the author makes the time and price analysis. The first stage of the second functions is the price of pork and the time, the price of pork and the time is two times, the price of pork and the time is a function of the third stages. In the three stages, the model is as follows. 
$\mathrm{P}$

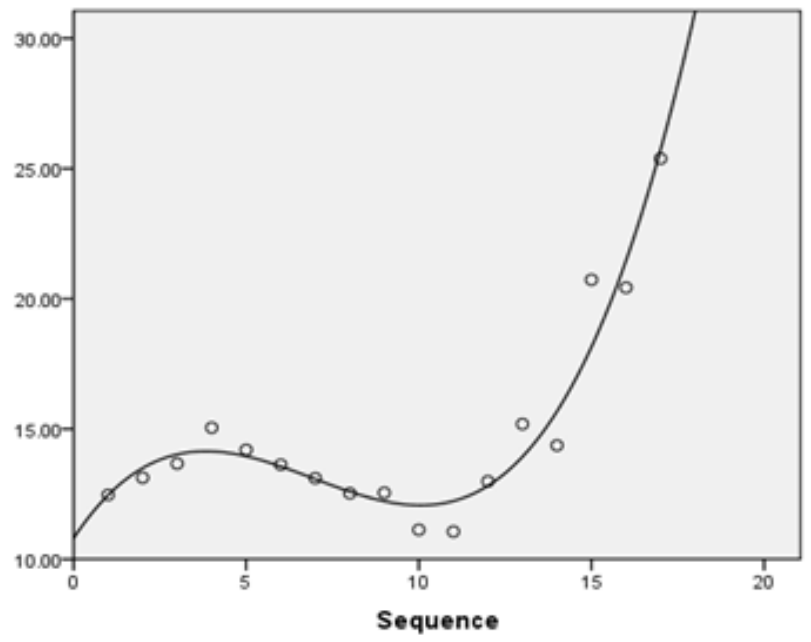

OObserved

Figure 2. Pork Price and the Time Function in the First Stage

$\mathrm{P}$

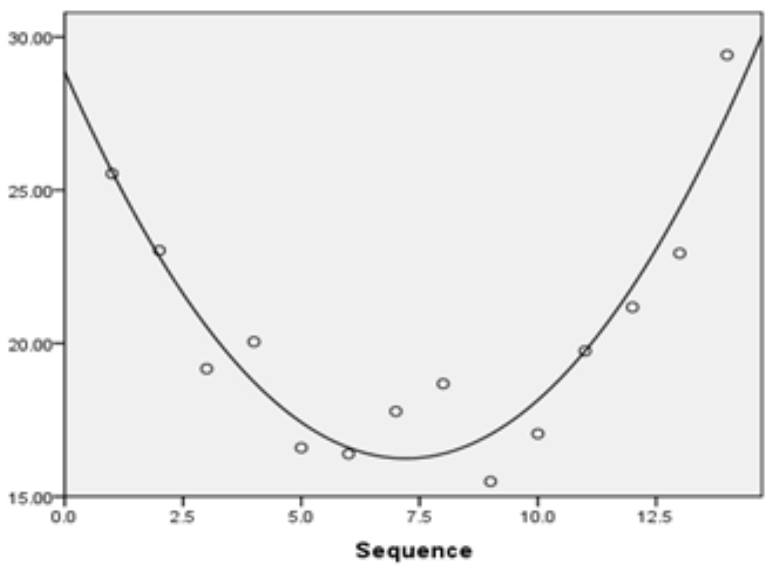

- Observed

Figure 3. Pork Price and the Time Function in the Second Stage

Ps

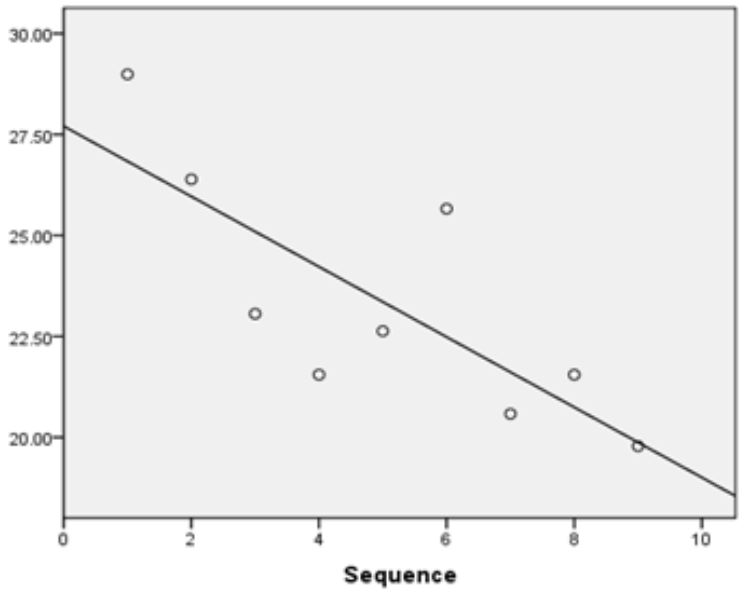

- Observed

Figure 4. Pork Price and the Time Function in the Third Stage 
Because the price fluctuation of the pork market has its inherent regularity, according to the price data of the system, the use of scientific methods and relevant background information to analyze the causes and influencing factors, grasp the law of price fluctuations, and then advance the market supply and demand and price changes, and ultimately to provide the corresponding information, and to introduce some appropriate market regulation measures. In the price fluctuations, the "iron" volatility, the long cycle, to avoid excessive fluctuations in the price of pork, pork prices stable at a relatively reasonable level, to maintain the healthy and sustainable development of the pork industry.

We make dependent variable as pork prices. From Figure 2, table 1 can be seen in the first phase of pork price and time to show a more obvious relationship between the three functions, including: linear coefficient of 1.998, showing a positive change in the relationship between the two coefficients is -0.360 , showing a negative correlation; the three coefficients is 0.017 , is now a positive change. Linear relationship in which the performance of the most obvious, the overall performance is on the rise, and after April 2007, pork prices showing a very clear upward trend.

From Figure 3, table 2 can be seen in the second stage, the price of pork and time is a more obvious relationship between the two functions, the linear coefficient is -3.504 , showing a reverse change relationship; the two coefficients is 0.243 , showing the same to the change. Therefore, the stage of pork prices from a high point to a low point, and from the low point of the roller coaster ride to the high point. From Figure 4, table 3 can be seen, in the third stage of pork prices and time to show a more obvious a function relationship, linear coefficient of -0.870 , showing a reverse change relationship, the stage of pork prices showing an overall downward trend.

Table 1. First Stage Model Overview and Parameter Estimation

\begin{tabular}{|l|l|l|l|l|l|l|l|l|l|}
\hline \multirow{2}{*}{ Equation } & \multicolumn{4}{|l|}{ Model Summary } & \multicolumn{4}{|l|}{ Parameter Estimates } \\
\cline { 2 - 11 } & R Square & F & df1 & df2 & Sig. & Constant & b1 & b2 & b3 \\
\hline Quadratic & 0.937 & 64.797 & 3 & 13 & 0.000 & 10.806 & 1.998 & -0.360 & 0.017 \\
\hline
\end{tabular}

Table 2.Second Stage Model Overview and Parameter Estimation

\begin{tabular}{|l|l|l|l|l|l|l|l|l|}
\hline \multirow{2}{*}{ Equation } & \multicolumn{4}{|l|}{ Model Summary } & \multicolumn{3}{|l|}{ Parameter Estimates } \\
\cline { 2 - 9 } & R Square & F & df1 & df2 & Sig. & Constant & b1 & b2 \\
\hline Quadratic & 0.890 & 44.621 & 2 & 11 & 0.000 & 28.864 & -3.504 & 0.243 \\
\hline
\end{tabular}

Table 3.Third Stage Model Overview and Parameter Estimation

\begin{tabular}{|l|l|l|l|l|l|l|l|}
\hline \multirow{2}{*}{ Equation } & \multicolumn{4}{|l|}{ Model Summary } & \multicolumn{2}{l|}{ Parameter Estimates } \\
\cline { 2 - 8 } & R Square & F & df1 & df2 & Sig. & Constant & b1 \\
\hline Linear & 0.615 & 11.176 & 1 & 7 & 0.012 & 27.705 & -0.870 \\
\hline
\end{tabular}

\subsection{Analysis on Price Fluctuation of Pork}

The 2004 -2013 ten years of pork prices showed a different trend, and China's pork consumption changes, pig breeding industry changes, policy changes have a close relationship. January 2004 -2008 January years, the price of pork showing a S type of change, which is closely linked with the constant changes in the cost of pig breeding, aquaculture, and other factors, such as the size of the breeding. In 2004 and 2005, pig grain price respectively for $6.302,6.07$, is able to obtain relatively reasonable level of profit, although 2006 swine grain price is 5.41, but due to the pre breeding scale larger of 
inertia effect, resulting in the sustainable development of pig breeding industry, the steady growth of the number of pig slaughter, 2004, 2005 and 2006 the number of slaughter pigs respectively for 572.785 million, 60367.4 million, 61207.3 million, to speed up the growth rate obviously. This also led to a substantial decline in hog prices in 2006. 2007 due to the scale of pig breeding, combined with the impact of pig disease, the pig breeding industry has suffered heavy losses, which also led directly to the rapid growth of pork prices in April 2007 to January 2008.

From April 2008 to July 2011, the price of pork is showing a trend of V type, with the time of the government's pig farming subsidies and the inertia of pig breeding cycle has a close relationship. 2007 pork prices rose substantially since, China has issued a large number of pig farming subsidies, particularly to support the development of a standardized scale breeding field (District) of the building, which also in a certain extent, promote the development of pig breeding industry, make our country pig slaughter amount year after year to climb. This initial expansion in 2007, in 2008 began to lead to a new round of pork prices. The decline in the price of pork has caused panic among farmers, the scale of pig farms began to slow down, and the pork price continued to fall after a gradual increase in pork prices.

From October 2011 to October 2013 pork prices showing a downward trend fluctuations, mainly because this time scale pig farming gradually expanded, to the number of slaughter pigs, for example, the number of slaughter pigs in 2011, 2012, 2013, respectively for 66326.1 million, 69789.5 million, 71557.3 million, in terms of per capita consumption does not increase significantly, pork prices show a downward trend in the reason.

\section{Results and Discussions}

\section{1 .The Impact of Pork Price Fluctuation on Domestic Demand}

From China's pork is mostly in domestic consumption, so the price of the change is mainly to affect the domestic demand. According to industry information network released data show that in 2004 -2013 years of pork consumption was 43.042 million tons, 45.139 million tons, 46.014 million tons, 42.71 million tons, 46.691 million tons, 48.823 million tons, 51.157 million tons, 49.81 million tons, 51.94 million tons, 52.615 million tons. Pork consumption fell in the year of 2007 and 2011, respectively, compared with 2010 and 2006 consumption fell by $7.18 \%$ and $2.63 \%$. But compared with 2007 and 2011 pork prices rose by $55.24 \%$ and $47.68 \%$, pork consumption is much lower than pork prices rose. This also shows that the rise in pork prices can reduce pork consumption, but the impact is limited.

From 2004 to 2013 years, urban residents and rural residents per capita consumption of pork and pork consumption trends are basically consistent, regardless of urban residents per capita consumption of pork or rural residents are showing a rising trend, pork prices, pork consumption has declined, but the per capita pork consumption fell far below the price of pork. This also shows that the change of pork consumption per capita is not sensitive to the change of pork price. Compared with urban residents and rural residents per capita pork consumption, can be seen, the per capita consumption of pork per capita is higher than that of rural residents per capita consumption of pork, in 2004 to 2013 annual consumption of pork per capita, urban residents of $20.07 \mathrm{~kg} /$ person, rural residents of $14.23 \mathrm{~kg} /$ person, with China's urbanization process accelerated, urban population increase, pork consumption will have a greater rise in space. There are three reasons for this situation: first, the income level of urban and rural residents is gradually increasing, which promotes the consumption of pork. According to classical economics theory, in a certain market price, the most important factor is the income of the commodity consumption. Two residents have the traditional habit of consumption of pork, even when 
the price of pork is higher, people's consumption of pork is also maintained a high level. In rural areas there are a range of pork from slaughtered by cannibalism. In this case, the price of pork rose a smaller influence on the consumption of pork.

Through the above analysis, we can see that pork consumption has a broad space for growth, especially with the urbanization, urban and rural integration process, the continuous improvement of the income of residents, residents of pork consumption will show a rising trend. China's main pork producing areas in the eastern region, these areas are rich in material, transportation convenient, easy to implement large-scale breeding, but also conducive to the formation of the production, processing, marketing integration of the chain, can be more convenient to the surrounding areas, forming a relatively stable supply of pork.

\subsection{The Impact of Price Fluctuation on the Income of Farmers}

Pork prices and the decline, but also directly affect the economic income of farmers. In Table 4, listed in the $2004-2013$ between the national and Hunan, Shandong, Anhui pig industry output value. It is not difficult to see, the country and the province of the pig industry output value and pork price fluctuations show a high degree of fit. In 2007, 2011, 2008, pig industry output value has increased significantly, in 2005, 2006, 2009; the pig industry output value also has a different degree of decline.

Pork prices raising will attract more farmers or farmers to expand the scale of pig breeding, which will drive the rise in feed prices. Overall, the rise in pork prices can offset the decline in the price of pig feed prices, to increase the income of farmers. From 2004 2013 pig grain price changes, the year of the rise in pork prices, pig grain price is showing a trend of expansion, the year of the decline in pork prices, pig grain prices show a narrowing trend. In 2007, 2008, 2011 swine grain price respectively 754, 846, in $7.432005,2006,2009,2010$ swine grain price respectively is $6.07,5.41,648,567$. This also shows that the price of pork has a positive effect on the stable growth of farmers' income.

Table 4. List of Pig Industry Output Value (100 Million RMB)

\begin{tabular}{|l|l|l|l|l|l|l|l|l|l|}
\hline Year & China & Hunan & Shandong & Anhui & Year & China & Hunan & Shandong & Anhui \\
\hline 2004 & 3724.58 & 603.12 & 385.86 & 283.41 & 2009 & 5624.42 & 935.01 & 667.06 & 416.87 \\
\hline 2005 & 3689.79 & 610.09 & 396.23 & 269.78 & 2010 & 5801.45 & 1151.12 & 693.51 & 432.48 \\
\hline 2006 & 3348.36 & 575.20 & 383.14 & 250.80 & 2011 & 8577.38 & 1160.03 & 900.44 & 586.02 \\
\hline 2007 & 5076.76 & 804.04 & 514.77 & 334.97 & 2012 & 7875.14 & 1017.03 & 924.44 & 585.15 \\
\hline 2008 & 6912.27 & 1149.11 & 757.39 & 462.67 & 2013 & 8135.13 & 973.88 & 947.43 & 592.21 \\
\hline
\end{tabular}

\section{Conclusions}

From 2004 to 2013 this decade pork prices change analysis can be seen, fluctuations in the price of pork showing a periodic characteristic, and later in 2007, due to the rising cost of pig, pig cycle resulted in long difficult on the market price to make more clear determine the cause of the effect of pig industry development increased uncertainty and other factors, cause wide cyclical pattern of fluctuations in pork prices, prices generally have higher trend. Fluctuations of the price of pork will also impact on the industry's income.

To promote the healthy and stable development of the pig industry, it should be from five aspects: first, actively encourage large-scale breeding, and do a good job of prevention and control of swine industry. Land according to the actual situation, formulates policies and measures in line with practical support throughout the development of standardized farms. By using large-scale breeding can achieve the cost of breeding. Two is to encourage the development of the company added farmers' breeding form. Through large-scale pig industry companies and farmers in the form of cooperation, 
can enable farmers to enhance market risk resilience. Three is the establishment of production, supply, sales integration of supply chain, so that the supply of pork products in a wider range of circulation, reduce regional supply of excess, the situation of sluggish sales. Four is to make full use of the Internet and achieve the integration of the supply chain of pigs. Through the integration of information on various aspects of the National Pork and pig breeding industry, it will help to improve the stable development of pig breeding industry, and maintain the stable and orderly operation of pork prices. At the same time, we can also use the internet to create a pig industry information exchange platform to promote the orderly development of pig breeding industry. Five is the use of international trade to maintain the healthy development of the pig industry. Pork prices in the downturn, can reduce the downward pressure on domestic pork prices through exports, the price of pork can be too high to adjust the domestic pork prices too fast.

\subsection{Establishment of Pork Production and Supply Security Mechanism}

China's pork market is a basic closed domestic market. In the known total demand under the condition of no movement, regulation of the focal point is how to guarantee the security of supply; supply of pork is the key point of promoting the smooth development of production, to prevent sharp fluctuations in the price of pork production and. changing the status quo of China's pork market information shortage. The national and relevant agencies should forecast data from the national and provincial pork total demand forecast by research and analysis at the beginning of each year, and we can determine their own production plan according to the forecast, which can provide more information for the farmers' breeding and improve the stability of the farmers' production.

The consumption demand of the future market of pork in China may reach 70 million tons, and the standard size of feeding can be from the scientific feeding and fine feeding, that is, using the standard production model to develop the pig breeding industry. The government should do is to support a large number of leading enterprises, to encourage them to raise the level of scale and level of feeding. In the overall planning and support of the country, with technology as the support, focus on the development of a group of pork industry leading enterprises, the formation of a few major areas of pork production areas, so that they become the stability of China's pork industry and the leading force.

To establish a scientific and effective training system for pig breeding, accelerate the popularization of improved varieties of the market share in the cultivation of varieties, varieties should focus on the introduction and improvement of the combination, "cited, breeding, propagation, push chain, excellent pig scale as soon as possible will be good quality, strong resistance and high production performance, improve pork production capacity. The government should be based on the number of live pigs, slaughter number, support the establishment of breeding farms, the government bidding, business operation, accelerate the promotion of improved varieties, improve the quality of live pig and pork market

\subsection{Perfect Pork Market System}

Market, government and farmers have their respective responsibilities and behaviors in the price system of pork. Market cannot solve the problem, the government should promptly fill. According to the existing system has been established by the relevant functional departments in the week, month, quarter, respectively, feed prices and other market information, to remind farmers to control the breeding structure, to avoid market risks. The rest involved in the production of pig market, sales, consumer links can be fully regulated by the market, can be fully cleaned up the current policy support policies.

The establishment of technology application integration, the use of industrial organization form, promoting the integration of industry, strengthens the demonstration and promotion of new varieties of new technologies. In particular, to encourage the 
establishment of the intermediate organization of the industry chain, to really play their role in the promotion of the development of pork industry. To promote industrial integration process and reduce the risk of market chain dispersion. In particular, to change the current industry chain of the main interests of the mechanism is not scientific and unreasonable; the government should introduce the relevant supervision and management measures. The government can set up major merchandise reserve system and establish a price regulation fund to control prices and stabilize the market. When hog prices are too high or too low, through appropriate storage or production subsidies, subsidies for lowincome groups and other measures to smooth fluctuations in hog market, alleviate the impact of rising pork prices over the low income groups

\subsection{Improve the Effectiveness of Policy Regulation}

Change the current regulation and control policies to respond to the introduction of the right, the introduction of a time is not appropriate, the way is not reasonable subsidies, support means a single, the regulation is not formed, and other status quo. In the regulation policy issued before the first in-depth study of the fundamental problem of market price fluctuation in where, only understand this fundamental question, the policy targeted can be targeted. Secondly, in the choice of means of regulation, the feasibility to scientific appraisal methods, mechanism and the role of the timely tracking judged means. Finally, in the choice of control time, to fully comply with the objective laws of the production and circulation of pork, the accurate time to enter the regulation and control mechanism, to achieve the purpose of effective regulation.

From the perspective of policy regulation and control itself, the price of pork must be controlled in the short term, and it should be adjusted to the active regulation, and it should pay more attention to the nodes and continuity of regulation. From the point of view of regulation, regulation and control in the production process, stable production at the same time, pay more attention to the regulation and control of the market, in the respect of the basic mechanism of market regulation, the reasonable identification of government regulation should be involved in the field.

\section{Acknowledgments}

The work of this paper is supported by Anhui province colleges and universities outstanding young talent support program key project funded results; Outstanding academic and technical backbone of Suzhou University (No.2014XJGG13); Key research project of Humanities and Social Sciences in Universities in Anhui Province "The context of urban and rural areas in northern rural living environment present situation and countermeasure" (No. SK2015A570).

\section{References}

[1] C. Guo and G. Pan, "Some thoughts on the daily supervision of prepackaged food: a discussion on the supervision of prepackaged food labels", Chinese business \& administration research, vol.12, (2012), pp. 47-49.

[2] S. Oddvin and H. Martin, "Effects of food ingredients and oxygen exposure on premature browning in cooked beef", Meat Science, vol. 1, (2013), pp. 105-110.

[3] Y. Xiaohua, "Where have all the pigs gone? Inconsistencies in pork statistics in China", China Economic Review, vol. 30, (2014), pp. 469-484.

[4] Y. Chen, "Understanding of food nutrition label pilot scientific and healthy living standards", Chinese health standard management, vol. 5, (2012), pp. 77-79.

[5] H. Jiqin and H. Jacques, "Relationship and quality management in the Chinese pork supply chain", International Journal of Production Economics, vol. 134, (2011), pp. 312-321.

[6] G. Li and S. Xu, "Using Quantile Regression Approach to Analyze Price Movements of Agricultural Products in China," Journal of Integrative Agriculture. vol.11, (2012), pp. 674-683.

[7] Z. Liu and T. Lin, "Prepackaged food daily supervision of a few thinking:on the prepackaged food product labels regulatory", modern food science and technology, vol. 5, (2011), pp. 580-583. 
International Journal of Future Generation Communication and Networking

Vol. 9, No. 2 (2016)

[8] S. Teresa, and Z. David, "Biofuel-related price transmission literature: A review", Energy Economics, vol. 37, (2013), pp. 141-151.

[9] L. Wu, "Sino Japanese experts jointly promote the implementation of the system of nutrition", Chinese and foreign food, vol. 3, (2012), pp. 71-73.

[10] Z. Zhou, "Definition of prepackaged food from the new standard", Jiangxi food industry, vol. 3, (2011), pp. 7-8.

[11] A .Kym, "Trade Barrier Volatility and Agricultural Price Stabilization", World Development, vol. 40, (2012), pp. 36-48. 